\title{
Prognostic significance of galectin-1 expression in patients with cancer: a meta-analysis
}

\author{
Rongzu Wu ${ }^{1,2 \dagger}$, Tingchun $\mathrm{Wu}^{2 \dagger}$, Kai Wang ${ }^{2}$, Shicheng Luo ${ }^{2}$, Zhen Chen², Min Fan ${ }^{2}$, Dong Xue ${ }^{2}, \mathrm{Hao} \mathrm{Lu}^{2}$, \\ Qianfeng Zhuang ${ }^{2^{*}}$ and Xianlin $\mathrm{Xu}^{3^{*}}$ (1)
}

\begin{abstract}
Background: The prognostic significance of galectin-1 (Gal-1) expression in cancerous patients has been assessed for several years while the results remain controversial. Thus, we performed the first comprehensive meta-analysis to evaluate the prognostic value of Gal-1 expression in cancerous patients.

Methods: We searched Pubmed, Embase and Web of Science to recruit studies on the prognostic impact of Gal-1 expression in cancerous patients. Eighteen studies containing 2674 patients were involved in this meta-analysis until March 30, 2018. Pooled hazard ratios (HRs) with 95\% confidence interval $(95 \% \mathrm{Cl})$ were calculated to estimate the effect using random-effects model.

Results: The pooled results revealed that high Gal-1 expression in cancer tissue associated with a poor OS (HR $=1.79$, $95 \% \mathrm{Cl} 1.54-2.08, \mathrm{P}<0.001)$. In the subgroup of tumor type, it's observed that high Gal-1 expression was significant correlated with poor OS in digestive cancers without heterogeneity $(\mathrm{HR}=1.94,95 \% \mathrm{Cl} 1.64-2.30, \mathrm{P}<0.001$; fixedeffects model; $I^{2}=20.1 \%, P=0.276$ ).

Conclusions: Our present meta-analysis indicates that high Gal-1 expression might be a predictive factor of poor prognosis in cancers, particularly in digestive cancers.
\end{abstract}

Keywords: Galectin-1, Cancer, Prognosis, Meta-analysis

\section{Background}

Cancer has been a globally severe health problem. As demonstrated by the data from NCHS, about 1,658,370 people were newly diagnosed with cancers and about 589,430 cancerous patients died in the year of 2015 [1]. Although the survival rate of cancer patients have been increasing in the last decades, the latest diagnostic approaches with better sensitivity and specificity are needed to accurately detecting and treating cancers [2].

\footnotetext{
*Correspondence: zhuangqianfeng19@163.com; xuxianlincz@163.com

${ }^{\dagger}$ Rongzu Wu and Tingchun Wu contributed equally to this manuscript.

${ }^{2}$ Department of Urology, The Third Affiliated Hospital of Soochow

University, Changzhou, Jiangsu, China

${ }^{3}$ Department of Urology, Sir Run Run Shaw Hospital, The Third Affiliated

Hospital of Nanjing Medical University, Jiangning District, Nanjing,

Jiangsu, China

Full list of author information is available at the end of the article
}

Thus, finding better tumor biomarkers is really important to improve the sensitivity and specificity, increasing the efficiency of detecting and treating cancers.

The galectin (Gal) family is a family of endogenous lectins with high affinity for polysaccharides including $\beta$-galactosyl residues and a part of animal lectins in the lectin family. Nowadays, 15 members have been found out in the lectin family, which have highly carbohydrate recognition domain (CRD). Galectin-1 (Gal1 ) is a secretion from cells and can bind and cross-link glycoconjugates on the cell surfaces, which includes various integrins and glycoproteins of the extracellular matrix (ECM) [3]. Besides, Gal-1 expression is regularly increased in tumor tissues since it can modulate cell adhesion, migration, survival and signaling [4]. At present, it has been clarified by some clinical studies that the expression of Gal-1 has close association with metastasis,

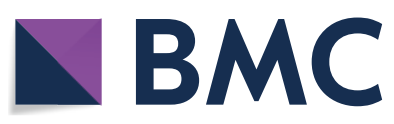

(c) The Author(s) 2018. This article is distributed under the terms of the Creative Commons Attribution 4.0 International License (http://creativecommons.org/licenses/by/4.0/), which permits unrestricted use, distribution, and reproduction in any medium, provided you give appropriate credit to the original author(s) and the source, provide a link to the Creative Commons license, and indicate if changes were made. The Creative Commons Public Domain Dedication waiver (http://creativecommons.org/ publicdomain/zero/1.0/) applies to the data made available in this article, unless otherwise stated. 
recurrence and bad tumor prognosis, which includes cholangiocarcinoma [5], gastric cancer [6-8], gingival squamous cell carcinoma [9], hepatocellular cancer [10-12], renal cell cancer [13], head and neck squamous cell carcinomas [14], ovarian cancer [15, 16], non-small cell lung cancer [17, 18], classic Hodgkin lymphoma [19], laryngeal squamous cell carcinomas [20], glioblastoma $[21,22]$ and so on. Nevertheless, we still don't clearly know the impact of Gal-1 on the consistency and magnitude of the prognosis. Therefore, we combined all those published evidences in a systematical manner so as to expose the relationship of Gal-1 and cancerous patients' prognosis for different kinds of tumors. We attempted to find out whether Gal-1 could help the treatment and prognosis of cancerous patients.

\section{Materials and methods}

This meta-analysis was based on the Preferred Reporting Items for Systematic Reviews and Meta-Analyses (PRISMA) guidelines [23].

\section{Search strategy}

The literature was done via PubMed, Embase and Web of Science databases. Keywords were "carcinoma OR cancer OR neoplasm OR tumor OR tumour" (in all fields) AND "prognostic OR prognosis OR outcome OR survival" (in all fields) AND "Galectin1 OR Galectin-1 OR Gal-1" (in all fields). The latest study was done on March 30, 2018. References of identified literature were also screened to further identify the related researches. Two authors independently searched the database. (Wu Rongzu and Wu Tingchun).

\section{Criteria for inclusion and exclusion}

The following criteria must be met for those literatures eligible for inclusion in this meta-analysis:

1. Gal-1's expression in cancer tissue.

2. Investigating the association between the level of expression of Gal-1 and survival outcome, which includes overall survival (OS), cancer-specific survival (CSS), disease-free survival (DFS), relapse-free survival (RFS) or progression-free survival (PFS).

3. Offering enough data for the estimation of $H R$ and $95 \%$ CI.

When several researches found out the same patient cohort, the whole or the latest cohort was included, with the exclusion of letters, editorials, expert opinions, reviews, case reports and non-human trials. Some researches without critical data for comprehensive analysis were also excluded. Besides, researches with sample sizes less than 40 were not included. The titles and abstracts of determined literatures were independently assessed by two viewers and the irrelevant literature was excluded. The enrolled articles were comprehensively evaluated and further screened by carefully viewing the whole text. Disagreement (if any) was resolved with negotiation.

\section{Data extraction and quality assessment}

Two researchers independently collected the required data from all available studies, including surname of the first author, the date of publication, origin of population, type of tumors, size of sample, mean or median age, gender of patients, stage of tumor, cut-off value, methods for tumor detection, results, and HR and 95\% CI of the high Gal-1 expression group versus the low Gal-1 expression group for OS, CSS, DFS, and RFS, if applicable. For those studies without HRs, the survival information was extracted from the raw data (KaplanMeier curves) by applying the Engauge Digitizer 4.1, and the data about survival rate was calculated with Tierney's method [24]. If both the results of univariate and multivariate analysis were reported in a study, only the latter was chosen since its accuracy increased when the confounding factors were considered.

By referring to the Newcastle-Ottawa quality assessment scale (NOS), two reviewers evaluated each study's quality systematically and independently [25]. A score of 0 was regarded as the poorest quality while 9 the highest quality. A study whose score was no less than six shall be considered as high quality.

\section{Statistical analysis}

The definition of high expression of Gal-1 was made based on the cut-off values given by the authors. The association between Gal-1 expression and cancerous patients' prognosis was described applying the pooled HRs and their 95\% CIs. The evaluation of heterogeneity was made by applying Cochran's Q test and Higgins I-squared statistics. $\mathrm{I}^{2}>50 \%$ and/or $\mathrm{P}<0.1$ suggested a obvious heterogeneity in terms of statistics, according to which a random effect model could be utilized. Alternatively, a model with fixed-effect was needed. If there was the heterogeneity, its source should be explored through the subgroup analysis. The sensitivity analysis was done by omission of each single study so as to evaluate the stability of results. The publication bias was assessed via the Begg and Egger funnel plot. In this meta-analysis, STATA software version 12.0 (Stata Corporation, College Station, TX, USA) was applied. A $\mathrm{P}$-value $<0.05$ could suggest statistical significance. 


\section{Results}

\section{Study characteristics}

As for the strategy used for search, totally 253 references were retrieved at the beginning. When the titles, abstracts, types of publication and overall text were comprehensively screened, the relationship between Gal-1 expression and the outcomes of patients with various malignant tumors were studied in 33 articles. In addition, 15 articles were not included (Gal-1 was detected not in tumor tissue in 8 articles, some key data were lacked in 2 articles, the sample size of 1 articles was less than 40, Only DSS (not OS) was discussed in 3 articles while DFS (not OS) was discussed in 1 article. Eventually, 18 articles were added into the meta-analysis when the comprehensive assessment was done (Fig. 1). Totally 2674 patients from China, Japan, Hungary, Argentina, Belgium, Germany, Denmark and USA were diagnosed with different cancers, such as cholangiocarcinoma, gastric cancer, gingival squamous cell carcinoma, hepatocellular cancer, renal cell cancer, head and neck squamous cell carcinomas, ovarian cancer, non-small cell lung cancer, classic Hodgkin lymphoma, laryngeal squamous cell carcinomas, glioblastoma and so on. The design of all studies was done retrospectively and the year of publication was between 2005 and 2018. 12 studies targeted Asians while six Caucasians. Totally 18 studies reported OS, while CSS and DFS were assessed only in two studies. OS was selected as the major survival outcome for all of the available studies in our meta-analysis. 7 studies reported HRs with their 95\% CIs. Through the graphical survival plots, the data was extracted in 11 studies. The cut-off values of Gal-1 differed in different studies. Table 1 demonstrates the significant features of these 18 available studies.

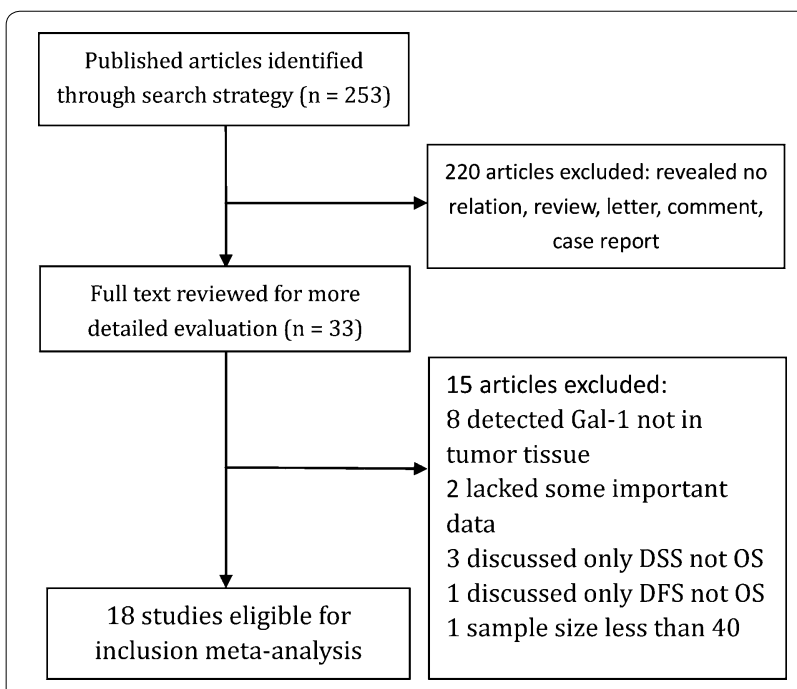

Fig. 1 Study identification flowchart
Figure 2 is show how different tumor types are distributed amongst studies and patients.

\section{Quality assessment}

The quality of all those 18 available studies in our metaanalysis was evaluated based on the NOS. The selection bias was observed in each and every study, maybe because only a single type of cancer was included in each study. Therefore, any study in this meta-analysis failed to represent the whole range of cancers. The study quality was between 6 and 7, with a mean value of 6.6. A larger value suggested a better methodology. Thus, the subsequent analysis included all available studies.

\section{Meta-analysis results}

Table 2 demonstrates the main results of this meta-analysis. Since the studies which evaluated OS have significant statistical heterogeneity $\left(\mathrm{I}^{2}=43.6 \%, \mathrm{P}=0.025\right)$, a model with random-effects was applied to get the HRs pooled. As shown by the statistical results, high expression of Gal-1 is obviously correlated with poor OS in various carcinomas, with the pooled $\mathrm{HR}$ of $(\mathrm{HR}=1.79,95 \% \mathrm{CI}$ 1.54-2.08, $\mathrm{P}<0.001$ ) (Fig. 3).

In order to study these studies' heterogeneity, subgroup analysis was done on the basis of four important characteristics, i.e. type of tumor, ethnicity, type of analysis and methods used for obtaining HR. In the subgroup of tumor type, it's observed that high Gal-1 expression was correlated with poor OS in digestive cancers without heterogeneity $(\mathrm{HR}=1.94,95 \% \mathrm{CI} 1.64-2.30, \mathrm{P}<0.001$; fixed-effects model; $\mathrm{I}^{2}=20.1 \%, \mathrm{P}=0.276$ ) (Fig. 4a) and in not digestive cancers with obvious heterogeneity $(\mathrm{HR}=1.61,95 \%$ CI 1.33-1.94, $\mathrm{P}<0.001$; random-effects model; $\mathrm{I}^{2}=42.5 \%, \mathrm{P}=0.066$ ) (Fig. $4 \mathrm{~b}$ ). In the subgroup of Caucasian, there is also without heterogeneity, with the pooled HR of $(\mathrm{HR}=1.42$, 95\% CI 1.21-1.66, $\mathrm{P}<0.001$; fixed-effects model; $\mathrm{I}^{2}=0.00 \%, \mathrm{P}=0.716$ ) (Fig. $5 \mathrm{~b}$ ). However, in other subgroups, the correlation between high Gal-1 expression and poor OS have statistical significance but with obvious statistical heterogeneity, including Asians $(\mathrm{HR}=1.96,95 \% \mathrm{CI} 1.60-2.42, \mathrm{P}<0.001$; model with random-effects; $\mathrm{I}^{2}=50.5 \%, \mathrm{P}=0.023$ ) (Fig. 5a), data extrapolated $(\mathrm{HR}=1.77,95 \%$ CI $1.42-2.20, \mathrm{P}<0.001$; random-effects model, $\left.\mathrm{I}^{2}=47.6 \%, \mathrm{P}=0.039\right)$, reported in text $(\mathrm{HR}=1.77,95 \%$ CI 1.42-2.20, $\mathrm{P}<0.001$; randomeffects model; $\mathrm{I}^{2}=49.2 \%, \mathrm{P}=0.066$ ), univariate analysis $(\mathrm{HR}=1.79,95 \%$ CI 1.54-2.09, $\mathrm{P}<0.001$; random-effects model; $\left.\mathrm{I}^{2}=50.0 \%, \mathrm{P}=0.008\right)$, Only multivariate analysis with no heterogeneity ( $\mathrm{HR}=1.93,95 \%$ CI $1.60-2.32$, $\mathrm{P}<0.001 ;$ fixed-effects model; $\mathrm{I}^{2}=0.0 \%, \quad \mathrm{P}=0.572$ ) (Table 2). 


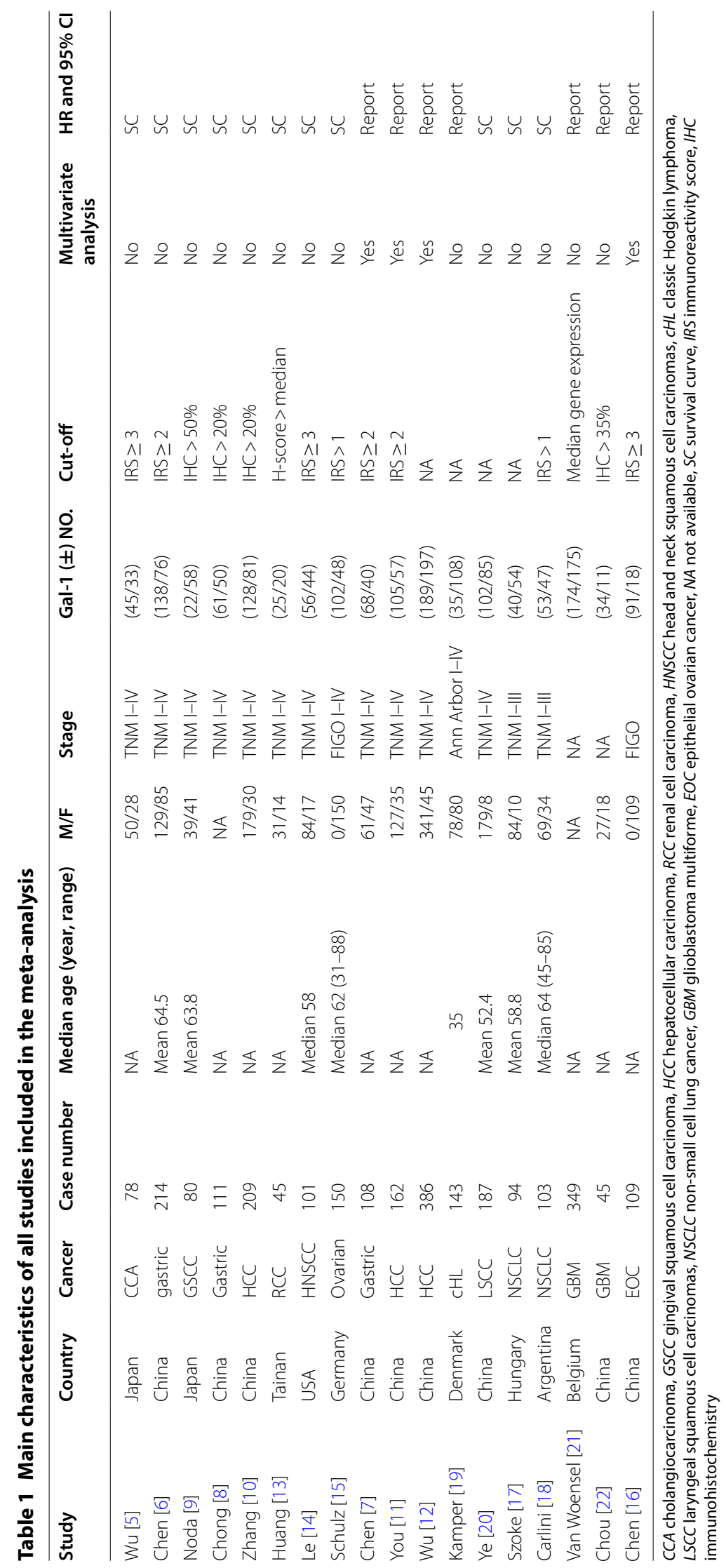




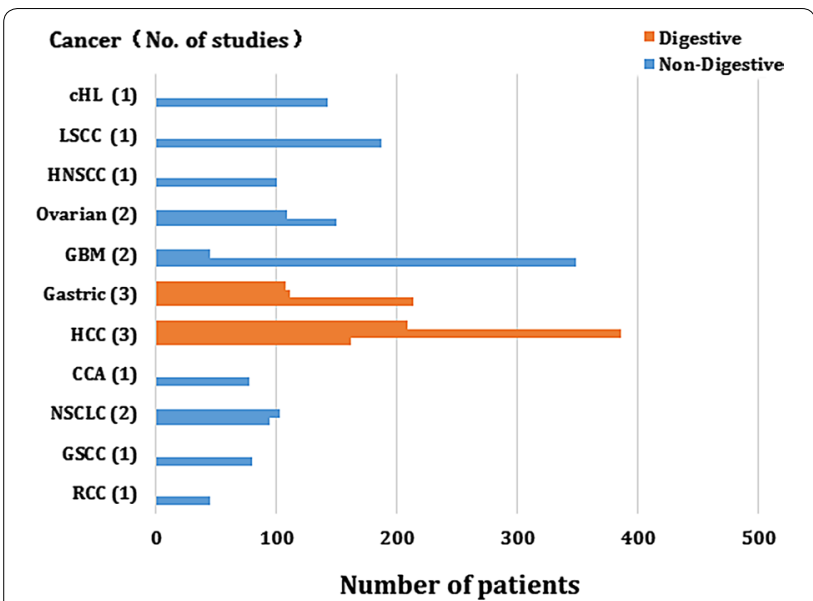

Fig. 2 Tumor types are distributed amongst studies and patients. CCA cholangiocarcinoma, GSCC gingival squamous cell carcinoma, HCC hepatocellular carcinoma, RCC renal cell carcinoma, HNSCC head and neck squamous cell carcinomas, CHL classic Hodgkin lymphoma, LSCC laryngeal squamous cell carcinomas, NSCLC non-small cell lung cancer, GBM glioblastoma multiforme

\section{Sensitivity analysis}

Sensitivity analysis was done through the sequential omission of single studies using a model with fixedeffects, and the result pattern was not obviously impacted by any single study (Fig. 6).

\section{Publication bias}

The assessment of the publication bias for OS was done through Begg's funnel plot and Egger's test. The shape of the funnel plot revealed some evidence of asymmetry (OS, $\mathrm{P}=0.103$ for the Begg's test, $\mathrm{P}=0.002$ for the Egger's test) (Fig. 7). After adjustment with the trim-and-fill method, the pooled association between Gal-1 expression and $O S$ in tumor patients was also significant (fixedeffects model: $\mathrm{HR}=1.49,95 \%$ CI 1.36-1.64, $\mathrm{P}<0.001$; random model: $\mathrm{HR}=1.53,95 \% \mathrm{CI} 1.30-1.80, \mathrm{P}<0.001)$, and with significant heterogeneity $(\mathrm{P}<0.001)$. Thus, the results of this meta-analysis are reliable.

\section{Discussion}

Although the past decades have witnessed great achievements in preventing and treating cancers, lots of cancers can't be treated or cured. Two of the major reasons are the lack of effective biomarkers required for early detection and the inefficient treatment of cancers diagnosed at the terminal stages. As shown by many researches, the expression of Gal-1 has statistically clinical significance, indicating Gal-1 might be a potential biomarker for the prognosis of cancers. Gal-1 is the prototype member of the Galectin superfamily, with the characteristics of high affinity binding to $\beta$-galactosides via a well-conserved carbohydrate recognition domain (CRD) [26]. Gal-1 can bind and cross-link glycoconjugates on the cell surfaces and regulate various biological processes, such as $\mathrm{T}$ cell homeostasis, resolution of inflammatory responses, host-pathogen interactions, selective deletion of specific thymocytes during $\mathrm{T}$ cell development, fetomaternal tolerance, and embryogenesis [3, 27-29]. Besides, it's known that high levels of Gal-1 expressed broadly over primary tumor sections via immunohistochemistry [30-32]. In the tumor microenvironment, Gal-1's upregulation benefits the tumor growth and reinforces the tumor progression by the modulation of cell motility [33], inducing apoptosis of activated $\mathrm{T}$ cells [34], mediation of cell

Table 2 The pooled associations between Gal-1 expression and the prognosis of cancerous patients (OS)

\begin{tabular}{|c|c|c|c|c|c|c|c|}
\hline \multirow[t]{2}{*}{ Outcome subgroup } & \multirow[t]{2}{*}{ No. of studies } & \multirow[t]{2}{*}{ No. of patients } & \multirow[t]{2}{*}{ HR $(95 \% \mathrm{Cl})$} & \multirow[t]{2}{*}{$P$ value } & \multirow[t]{2}{*}{ Model } & \multicolumn{2}{|c|}{ Heterogeneity } \\
\hline & & & & & & $P^{2}(\%)$ & $\mathbf{P}$ \\
\hline All & 18 & 2674 & $1.79(1.54-2.08)$ & $<0.001$ & Random & 43.6 & 0.025 \\
\hline \multicolumn{8}{|l|}{ Ethnicity } \\
\hline Asian & 12 & 1734 & $1.96(1.60-2.42)$ & $<0.001$ & Random & 50.5 & 0.023 \\
\hline Caucasian & 6 & 940 & $1.42(1.21-1.66)$ & $<0.001$ & Fixed & 0.00 & 0.716 \\
\hline \multicolumn{8}{|l|}{ Tumor type } \\
\hline Digestive system & 7 & 1268 & $1.94(1.64-2.30)$ & $<0.001$ & Fixed & 20.1 & 0.276 \\
\hline NOT digestive system & 11 & 1406 & $1.61(1.33-1.94)$ & $<0.001$ & Random & 42.5 & 0.066 \\
\hline \multicolumn{8}{|l|}{ Analysis type } \\
\hline Univariate & 18 & 2674 & $1.79(1.54-2.09)$ & $<0.001$ & Random & 50.0 & 0.008 \\
\hline Multivariate & 4 & 765 & $1.93(1.60-2.32)$ & $<0.001$ & Fixed & 0.00 & 0.572 \\
\hline \multicolumn{8}{|l|}{ HR obtained method } \\
\hline Reported in text & 7 & 1302 & $1.77(1.42-2.20)$ & $<0.001$ & Random & 49.2 & 0.066 \\
\hline Data extrapolated & 11 & 1372 & $1.77(1.42-2.20)$ & $<0.001$ & Random & 47.6 & 0.039 \\
\hline
\end{tabular}




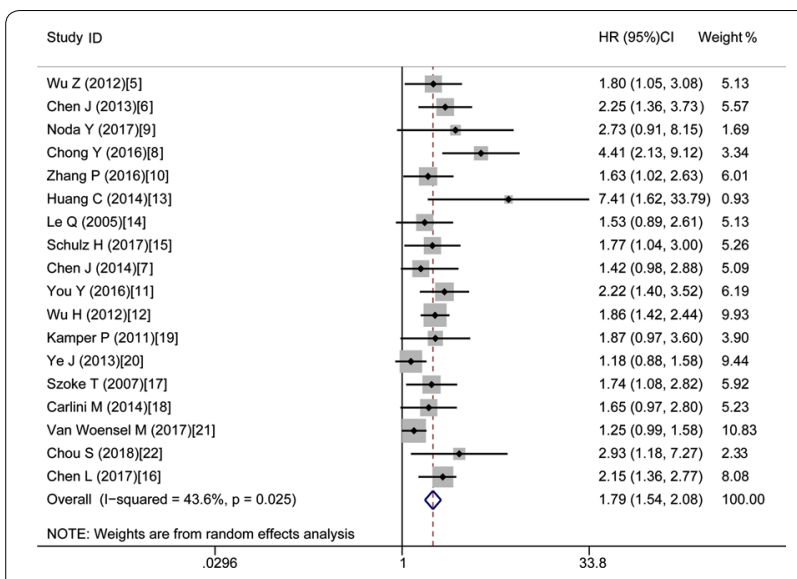

Fig. 3 Forest plots of studies assessing HR of high Gal-1 expression in cancers

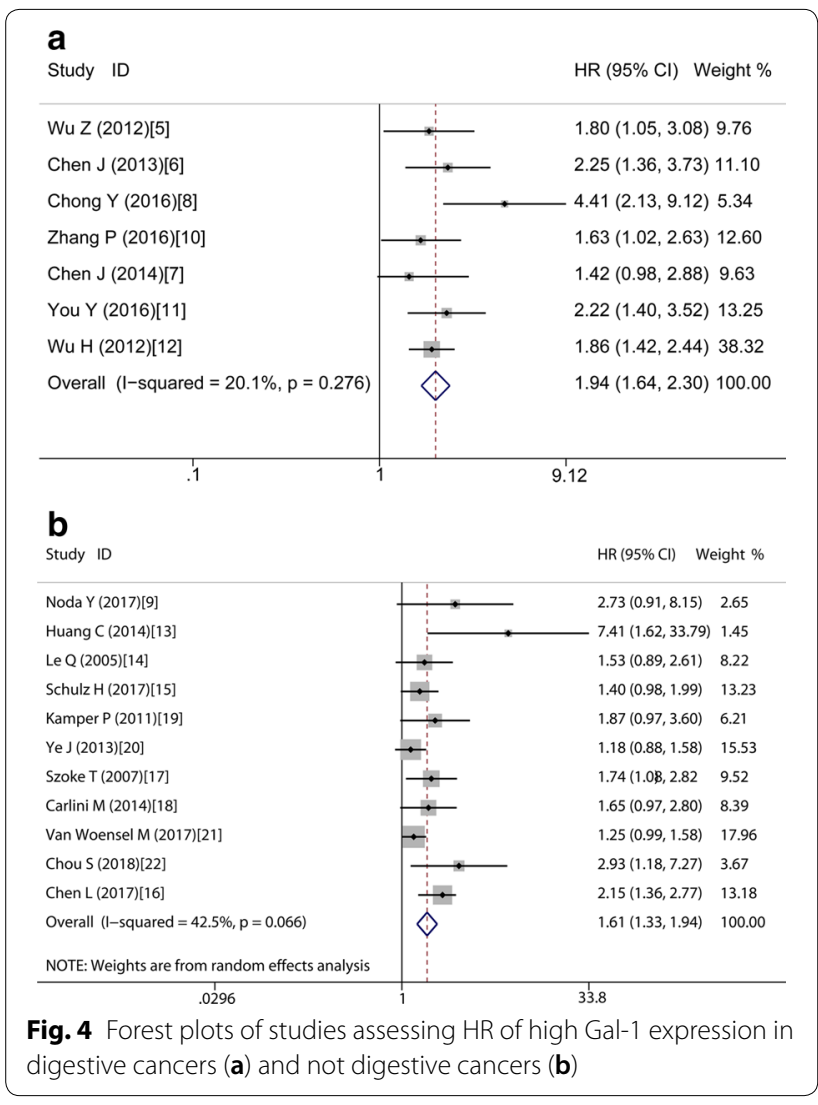

adhesion [35], and participation in tumor angiogenesis [36]. Besides, intracellular Gal-1 links oncogenic H-Ras to promote its anchorage to plasma membrane and stimulate the extracellular signal-regulated kinase (ERK) signaling pathway for neoplastic transformation [37]. Indeed, in most of the clinical studies, it's reported the raised level of Gal-1 is connected to the poor prognosis [7, 11,
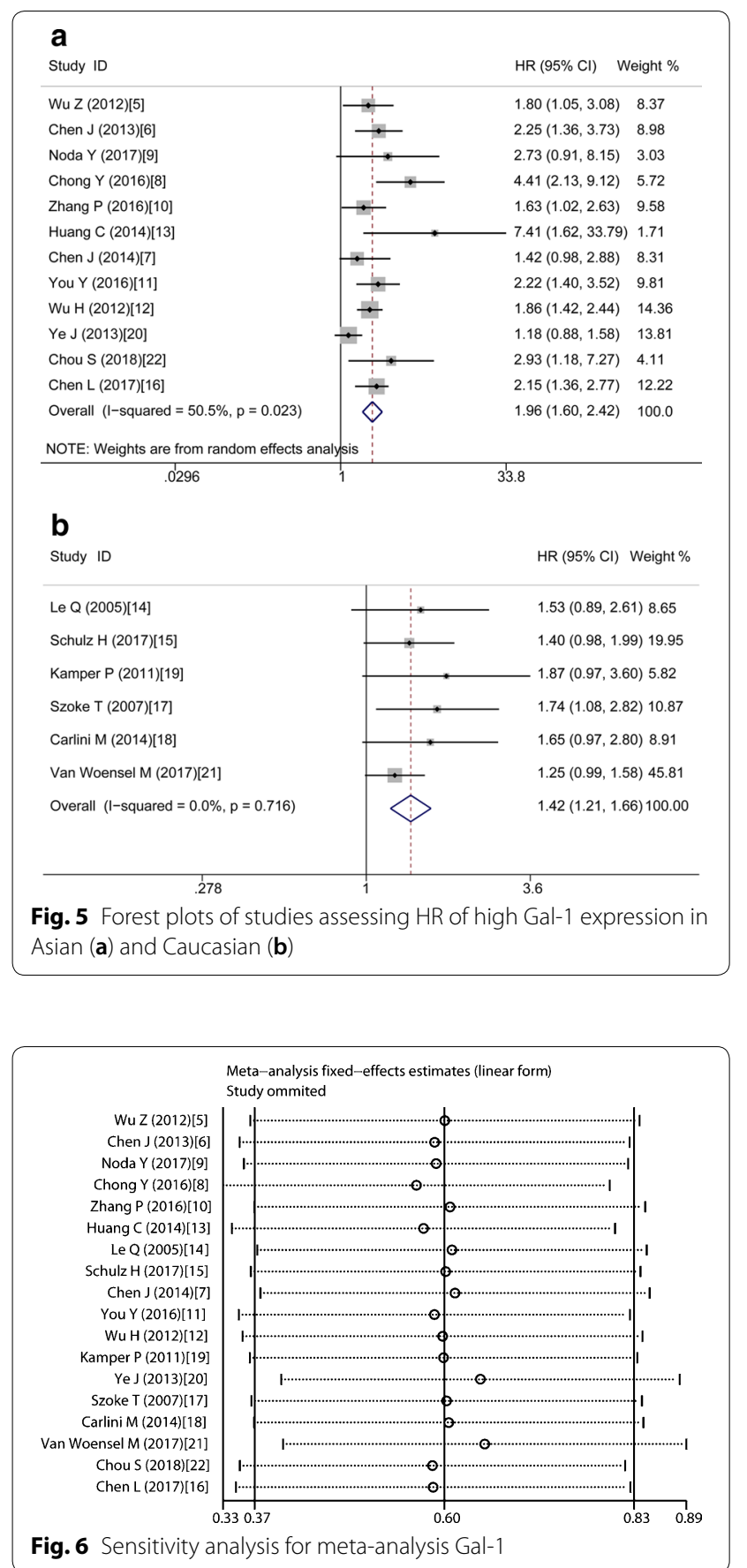

$13,20,22]$. On the other hand, although the relationship between Gal-1 expression and tumorigenesis has been studied intensively, no comprehensive analysis is done for the available data. Therefore, the consistency and scope regarding Gal-1's prognostic impact are unknown. As far as we know, except this one, there is no other meta-analysis focusing on the association between Gal-1 expression and cancerous patients' survival rate. 


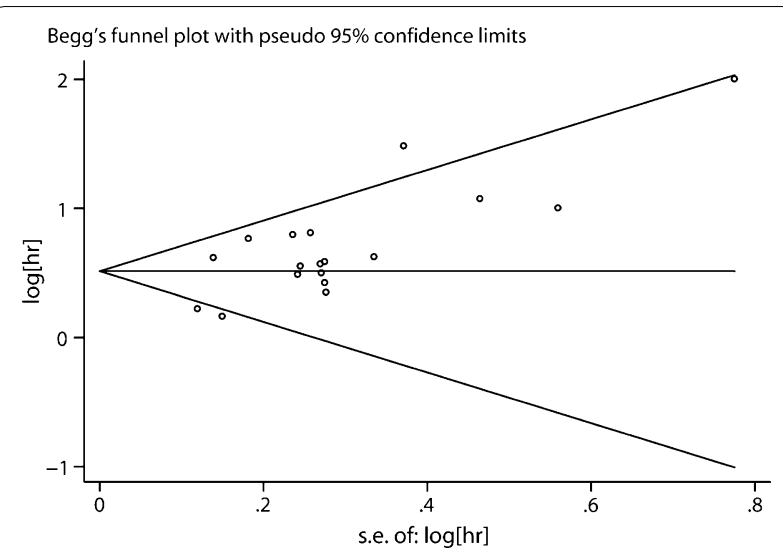

Fig. 7 Funnel plots for the evaluation of potential publication bias

This study demonstrates the relationship between high expression of Gal-1 in cancer tissue and a poor OS in cancerous patients with obvious statistical heterogeneity $\left(\mathrm{HR}=1.79,95 \%\right.$ CI $1.54-2.08, \mathrm{P}<0.001 ; \mathrm{I}^{2}=43.6 \%$, $\mathrm{P}=0.025)$. Nevertheless, in the analysis of subgroup, the elevated galectin-1 expression was considered as a bad prognostic marker in cancerous patients for OS, regardless of the kind of tumor, ethnicity, the kind of analysis and the method of obtaining HR. In particular, no obvious statistical heterogeneity is observed in digestive cancers, Caucasian and multivariate analysis $\left(\mathrm{I}^{2}<50 \%\right.$, $\mathrm{P}>0.1$ ). Thus, we believe that the heterogeneity of this meta-analysis mainly due to the difference in tumor type, patient, and type of analysis. In addition, all cut-off values are reported in the study, which may also lead to heterogeneity due to the absence of uniform standards. In summary, Gal-1 might function as a poor prognostic biomarker for cancerous patients, in particular, those of digestive origin and Caucasian.

This study is limited on several aspects. First, because of the missing of a unified cut-off value in Gal-1 expression, various cut-off values are utilized. This possibly exerts influences on the validity of Gal-1 as a predictive marker in the prognosis of cancer. Second, some HRs were computed according to the data gained from the survival curves, which unavoidably contributes to minor statistical errors. Finally, significant heterogeneity was shown, possibly because of the differences in patient origin, date of publication, kind of tumor, tumor stage, method used in the experiment, follow-up time, cut-off values and others. Since the current analysis has some limitations, more excellently-designed large-sized researches including more kinds of tumor should be done in the future.

\section{Conclusions}

This meta-analysis combined all researches, and attempted to study the relationship between the high expression of Gal-1 and the survival rate of cancerous patients. High Gal-1 expression can be used as a poor prognostic marker for tumors. This conclusion should be regarded carefully since the current analysis has some limitations. Given the sparse data, additional studies regarding Gal-1 are warranted.

\section{Abbreviations \\ HR: hazard ratio; 95\% Cl: 95\% confidence interval; CCA: cholangiocarcinoma; GSCC: gingival squamous cell carcinoma; HCC: hepatocellular carcinoma; RCC : renal cell carcinoma; HNSCC: head and neck squamous cell carcinomas; $\mathrm{CHL}$ : classic Hodgkin lymphoma; LSCC: laryngeal squamous cell carcinomas; NSCLC: non-small cell lung cancer; GBM: glioblastoma multiforme; EOC: epithelial ovarian cancer; NA: not available; SC: survival curve; IRS: immunoreactivity score; IHC: immunohistochemistry; OS: overall survival; CSS: cancer-specific survival; DFS: disease-free survival; RFS: relapse-free survival; PFS: progression- free survival; DSS: disease-specific survival.}

\section{Authors' contributions}

WR collected and analyzed the data, wrote the paper; TW analyzed the data; KW conceived and designed this study, analyzed the data; and all authors reviewed the paper. All authors read and approved the final manuscript.

\section{Author details}

${ }^{1}$ Department of Urology, XiShan People's Hospital, 1128 Anzhen Street, Wuxi 214011, Jiangsu, China. ${ }^{2}$ Department of Urology, The Third Affiliated Hospital of Soochow University, Changzhou, Jiangsu, China. ${ }^{3}$ Department of Urology, Sir Run Run Shaw Hospital, The Third Affiliated Hospital of Nanjing Medical University, Jiangning District, Nanjing, Jiangsu, China.

\section{Acknowledgements}

We would like to thank the researchers and study participants for their contributions.

\section{Competing interests}

The authors declare that they have no competing interests.

\section{Availability of data and materials}

All data generated or analysed during this study are included in this published article.

\section{Consent for publication}

Consent for publication was obtained from the participants.

\section{Ethics approval and consent to participate}

All procedures followed were in accordance with the ethical standards of the responsible committee on human experimentation (the Institutional Ethics Committee of the Third Affiliated Hospital of Soochow University) and with the Helsinki Declaration of 1964 and later versions.

\section{Funding}

This work was supported by the Youth Medical Talent Project of Jiangsu Province (QNRC2016292), China Postdoctoral Science Foundation (Grant No. 63, 2018M632371) and the Natural Science Foundation of Jiangsu Province (Grant Nos. BK20141161 and BK20150251). We thank AJE for its linguistic assistance during the preparation of this manuscript.

\section{Publisher's Note}

Springer Nature remains neutral with regard to jurisdictional claims in published maps and institutional affiliations. 
Received: 27 May 2018 Accepted: 31 July 2018

Published online: 03 August 2018

\section{References}

1. Siegel RL, Miller KD, Jemal A. Cancer statistics, 2015. CA Cancer J Clin. 2015;65(1):5-29.

2. Paul D, Kumar A, Gajbhiye A, Santra MK, Srikanth R. Mass spectrometrybased proteomics in molecular diagnostics: discovery of cancer biomarkers using tissue culture. Biomed Res Int. 2013;2013:783131.

3. Camby I, Le Mercier M, Lefranc F, Kiss R. Galectin-1: a small protein with major functions. Glycobiology. 2006:16(11):137R-57R.

4. Elola MT, Wolfenstein-Todel C, Troncoso MF, Vasta GR, Rabinovich GA. Galectins: matricellular glycan-binding proteins linking cell adhesion, migration, and survival. Cell Mol Life Sci CMLS. 2007;64(13):1679-700.

5. Wu Z, Boonmars T, Nagano I, Boonjaraspinyo S, Pinlaor S, Pairojkul C, Chamgramol $Y$, Takahashi Y. Alteration of galectin-1 during tumorigenesis of Opisthorchis viverrini infection-induced cholangiocarcinoma and its correlation with clinicopathology. Tumour Biol. 2012;33(4):1169-78.

6. Chen J, Zhou SJ, Zhang Y, Zhang GQ, Zha TZ, Feng YZ, Zhang K. Clinicopathological and prognostic significance of galectin-1 and vascular endothelial growth factor expression in gastric cancer. World J Gastroenterol. 2013:19(13):2073-9.

7. Chen J, Tang D, Wang S, Li QG, Zhang JR, Li P, Lu Q, Niu G, Gao J, Ye NY, et al. High expressions of galectin-1 and VEGF are associated with poor prognosis in gastric cancer patients. Tumour Biol. 2014;35(3):2513-9.

8. Chong Y, Tang D, Xiong Q, Jiang X, Xu C, Huang Y, Wang J, Zhou H, Shi Y, Wu $X$, et al. Galectin-1 from cancer-associated fibroblasts induces epithelial-mesenchymal transition through beta1 integrin-mediated upregulation of Gli1 in gastric cancer. J Exp Clin Cancer Res. 2016:35(1):175.

9. Noda Y, Kishino M, Sato S, Hirose K, Sakai M, Fukuda Y, Murakami S, Toyosawa S. Galectin-1 expression is associated with tumour immunity and prognosis in gingival squamous cell carcinoma. J Clin Pathol. 2017:70(2):126-33.

10. Zhang PF, Li KS, Shen YH, Gao PT, Dong ZR, Cai JB, Zhang C, Huang XY, Tian MX, Hu ZO et al. Galectin-1 induces hepatocellular carcinoma EMT and sorafenib resistance by activating FAK/PI3K/AKT signaling. Cell Death Dis. 2016;7:e2201.

11. You Y, Tan JX, Dai HS, Chen HW, Xu XJ, Yang AG, Zhang YJ, Bai LH, Bie P. MiRNA-22 inhibits oncogene galectin-1 in hepatocellular carcinoma. Oncotarget. 2016;7(35):57099-116.

12. Wu H, Chen P, Liao R, Li YW, Yi Y, Wang JX, Sun TW, Zhou J, Shi YH, Yang $\mathrm{XR}$, et al. Overexpression of galectin-1 is associated with poor prognosis in human hepatocellular carcinoma following resection. J Gastroenterol Hepatol. 2012:27(8):1312-9.

13. Huang CS, Tang SJ, Chung LY, Yu CP, Ho JY, Cha TL, Hsieh CC, Wang HH, Sun GH, Sun KH. Galectin-1 upregulates CXCR4 to promote tumor progression and poor outcome in kidney cancer. J Am Soc Nephrol. 2014;25(7):1486-95.

14. Le QT, Shi G, Cao H, Nelson DW, Wang Y, Chen EY, Zhao S, Kong C, Richardson D, O'Byrne KJ, et al. Galectin-1: a link between tumor hypoxia and tumor immune privilege. J Clin Oncol. 2005:23(35):8932-41.

15. Schulz H, Schmoeckel E, Kuhn C, Hofmann S, Mayr D, Mahner S, Jeschke U. Galectins-1, -3 , and -7 are prognostic markers for survival of ovarian cancer patients. Int J Mol Sci. 2017;18(6):1230.

16. Chen L, Yao Y, Sun L, Tang J. Galectin-1 promotes tumor progression via NF-kappaB signaling pathway in epithelial ovarian cancer. J Cancer. 2017:8(18):3733-41.

17. Szoke T, Kayser K, Trojan I, Kayser G, Furak J, Tiszlavicz L, Baumhakel JD, Gabius HJ. The role of microvascularization and growth/adhesion-regulatory lectins in the prognosis of non-small cell lung cancer in stage II. Eur J Cardiothorac Surg. 2007;31(5):783-7

18. Carlini MJ, Roitman P, Nunez M, Pallotta MG, Boggio G, Smith D, Salatino M, Joffe ED, Rabinovich GA, Puricelli LI. Clinical relevance of galectin-1 expression in non-small cell lung cancer patients. Lung cancer. 2014;84(1):73-8.

19. Kamper $P$, Ludvigsen M, Bendix K, Hamilton-Dutoit $S$, Rabinovich GA, Moller MB, Nyengaard JR, Honore B, d'Amore F. Proteomic analysis identifies galectin-1 as a predictive biomarker for relapsed/refractory disease in classical Hodgkin lymphoma. Blood. 2011;117(24):6638-49.

20. Ye J, Liu H, Hu Y, Wan G, Li J, Wang Z, Li P, Zhang G, Li Y. The clinical implication of tumoral Gal-1 expression in laryngeal squamous cell carcinomas. Clin Transl Oncol. 2013;15(8):608-18.

21. Van Woensel M, Mathivet T, Wauthoz N, Rosiere R, Garg AD, Agostinis P, Mathieu V, Kiss R, Lefranc F, Boon L, et al. Sensitization of glioblastoma tumor micro-environment to chemo- and immunotherapy by galectin-1 intranasal knock-down strategy. Sci Rep. 2017;7(1):1217.

22. Chou SY, Yen SL, Huang CC, Huang EY. Galectin-1 is a poor prognostic factor in patients with glioblastoma multiforme after radiotherapy. BMC Cancer. 2018;18(1):105.

23. Moher D, Liberati A, Tetzlaff J, Altman DG, Group P. Preferred reporting items for systematic reviews and meta-analyses: the PRISMA statement. BMJ. 2009;339:b2535.

24. Tierney JF, Stewart LA, Ghersi D, Burdett S, Sydes MR. Practical methods for incorporating summary time-to-event data into meta-analysis. Trials. 2007;8:16.

25. Stang A. Critical evaluation of the Newcastle-Ottawa scale for the assessment of the quality of nonrandomized studies in meta-analyses. Eur J Epidemiol. 2010;25(9):603-5.

26. Barondes SH, Castronovo V, Cooper DN, Cummings RD, Drickamer K, Feizi T, Gitt MA, Hirabayashi J, Hughes C, Kasai K, et al. Galectins: a family of animal beta-galactoside-binding lectins. Cell. 1994;76(4):597-8.

27. Blois SM, Ilarregui JM, Tometten M, Garcia M, Orsal AS, Cordo-Russo R, Toscano MA, Bianco GA, Kobelt P, Handjiski B, et al. A pivotal role for galectin-1 in fetomaternal tolerance. Nat Med. 2007:13(12):1450-7.

28. Rabinovich GA, Ramhorst RE, Rubinstein N, Corigliano A, Daroqui MC, Kier-Joffe EB, Fainboim L. Induction of allogenic T-cell hyporesponsiveness by galectin-1-mediated apoptotic and non-apoptotic mechanisms. Cell Death Differ. 2002;9(6):661-70.

29. Zuniga E, Gruppi A, Hirabayashi J, Kasai Kl, Rabinovich GA. Regulated expression and effect of galectin-1 on Trypanosoma cruzi-infected macrophages: modulation of microbicidal activity and survival. Infect Immun 2001;69(11):6804-12

30. Chiang WF, Liu SY, Fang LY, Lin CN, Wu MH, Chen YC, Chen YL, Jin YT. Overexpression of galectin-1 at the tumor invasion front is associated with poor prognosis in early-stage oral squamous cell carcinoma. Oral Oncol. 2008;44(4):325-34.

31. Kim HJ, Jeon HK, Cho YJ, Park YA, Choi JJ, Do IG, Song SY, Lee YY, Choi CH, Kim TJ, et al. High galectin-1 expression correlates with poor prognosis and is involved in epithelial ovarian cancer proliferation and invasion. Eur J Cancer. 2012;48(12):1914-21.

32. Saussez S, Cucu DR, Decaestecker C, Chevalier D, Kaltner H, Andre S, Wacreniez A, Toubeau G, Camby I, Gabius HJ, et al. Galectin 7 (p53induced gene 1): a new prognostic predictor of recurrence and survival in stage IV hypopharyngeal cancer. Ann Surg Oncol. 2006;13(7):999-1009.

33. Camby I, Belot N, Lefranc F, Sadeghi N, de Launoit Y, Kaltner H, Musette S, Darro F, Danguy A, Salmon I, et al. Galectin-1 modulates human glioblastoma cell migration into the brain through modifications to the actin cytoskeleton and levels of expression of small GTPases. J Neuropathol Exp Neurol. 2002;61(7):585-96.

34. Kovacs-Solyom F, Blasko A, Fajka-Boja R, Katona RL, Vegh L, Novak J, Szebeni GJ, Krenacs L, Uher F, Tubak V, et al. Mechanism of tumor cell-induced T-cell apoptosis mediated by galectin-1. Immunol Lett. 2010;127(2):108-18

35. Horiguchi $N$, Arimoto $K$, Mizutani A, Endo-Ichikawa Y, Nakada H, Taketani S. Galectin-1 induces cell adhesion to the extracellular matrix and apoptosis of non-adherent human colon cancer Colo201 cells. J Biochem. 2003:134(6):869-74

36. Thijssen VL, Postel R, Brandwijk RJ, Dings RP, Nesmelova I, Satijn S, Verhofstad N, Nakabeppu Y, Baum LG, Bakkers J, et al. Galectin-1 is essential in tumor angiogenesis and is a target for antiangiogenesis therapy. Proc Natl Acad Sci USA. 2006:103(43):15975-80

37. Paz A, Haklai R, Elad-Sfadia G, Ballan E, Kloog Y. Galectin-1 binds oncogenic $\mathrm{H}$-Ras to mediate Ras membrane anchorage and cell transformation. Oncogene. 2001;20(51):7486-93. 